\title{
Composição de resíduos de varrição e resíduos carreados pela rede de drenagem, em uma bacia hidrográfica urbana
}

\section{Litter composition delivered by street sweeping and by the storm drainage network, in an urban catchment}

\author{
Marllus Gustavo Ferreira Passos das Neves \\ Engenheiro Civil. Doutor em Recursos Hídricos e Saneamento Ambiental. Professor do Centro de Tecnologia da Universidade Federal de Alagoas (CTEC-UFAL)
}

Carlos Eduardo Morelli Tucci

Engenheiro Civil. Doutor em Recursos Hídricos. Professor do Instituto de Pesquisas Hidráulicas da Universidade Federal do Rio Grande do Sul (IPH-UFRGS)

\begin{abstract}
Resumo
Apresentam-se aqui resultados de estudo sobre a composição física de resíduos sólidos de varrição e também daqueles vindos por uma rede de drenagem, em uma bacia hidrográfica urbana, identificando, dentre outros, influências da frequência do serviço de varrição e da época do ano. Os resíduos de varrição foram provenientes de várias partes do solo da bacia e os da rede de drenagem eram retirados de um poço de casa de bombas, para onde convergia todo o escoamento da rede. Alguns resultados interessantes: em média, 23\% da massa de varrição são de lixo seco, predominando plásticos moles. Mais presença de plásticos duros ocorreu nas áreas de varrição diária. Com a análise dos resíduos vindos pela drenagem: o plástico Pet apareceu mais na rede em precipitações intensas do que nos sacos de varrição. Plásticos moles sempre ocorrem na varrição e na drenagem ao longo do ano.
\end{abstract}

Palavras-chave: resíduos sólidos; drenagem urbana; águas urbanas.

\section{Abstract}

This paper presents results of a study about physical composition of litter from street sweeping and also those delivered by a storm drainage network urban catchment, identifying, among others, influences of the frequency of sweeping service and the season. The litter from sweeping came from several parts of the catchment and those delivered by a storm drainage network were taken from a well pump house, convergence point of the flow. Some interesting results: on average, $23 \%$ of the street sweeping mass is dry litter, predominantly soft plastics. More presence of hard plastics occurred at areas of daily sweeping. With the analysis of litter in the storm drainage network: pet plastics are more delivered by storm drainage network in intense rainfall than appear in bags sweeping. Soft plastics always occur in the bags sweeping and into storm drainage network throughout the year

Keywords: litter; urban drainage; urban water.

\section{Introdução}

O desenvolvimento urbano envolve, dentre outros, a implementação de infraestrutura de abastecimento de água, coleta, disposição e tratamento de esgoto e de resíduos sólidos, drenagem de águas pluviais e limpeza pública. A gestão inadequada destes elementos é uma das causas dos impactos ambientais crescentes nas cidades. Observa-se ainda que os componentes citados possuem forte interface entre si, apesar de o mesmo não ocorrer com as soluções, devido à forma setorial como a gestão é realizada (TUCCI, 2002). Além disso, soluções para os problemas são mais difíceis nos países em desenvolvimento por causa das condições socioeconômicas, tecnológicas e climáticas mais difíceis (SILVEIRA, 2001), experimentando uma urbanização acelerada, mais em suas periferias do que em suas regiões centrais (TUCCI, 2002).

Neste contexto, os resíduos sólidos compõem o segundo estágio de produção de sólidos totais em uma bacia hidrográfica urbana, ocorrendo em áreas de ocupação consolidada (TUCCI, 2002). $\mathrm{O}$ efeito deste poluente na drenagem urbana é citado em diversos trabalhos de forma secundária desde a década de 1970 (SCHUELER, 1987), sendo poucos os trabalhos de quantificação e caracterização. 
Segundo Neves e Tucci (2008), existem mais estudos quando se trata da coleta domiciliar. No caso da varrição, os autores citam trabalhos que tratam do efeito da frequência de limpeza com totais na rede de drenagem. Estes trabalhos começaram a surgir na década de 1990 em países como África do Sul, Austrália e Nova Zelândia (ICNZT, 1996; ALLISON et al., 1998; ARNOLD; RYAN, 1999; ARMITAGE, 2001 apud MARAIS; ARMITAGE, 2004). Recentemente no Brasil, há uma busca mais acentuada por parâmetros de caracterização e quantificação na drenagem urbana (ARMELIN, 2005; BRITES, 2005; JAWOROWSKI, SCHETTINI, SILVEIRA, 2005; NEVES, 2006; NEVES, TUCCI, 2008).

O objetivo geral deste trabalho foi determinar a composição física de resíduos de varrição e dos resíduos carreados pela rede de drenagem, em uma bacia hidrográfica urbana, identificando influências da frequência do serviço de varrição e da época do ano e analisando conjuntamente as duas composições.

\section{Material e Métodos}

A análise da composição física dos resíduos de varrição das ruas da bacia hidrográfica foi realizada em sacos de varrição entre os meses de outubro de 2003 e junho de 2004, abrangendo um período quente de final de primavera e verão e um período frio de outono e início de inverno. Por não haver coincidência entre espaço geográfico da bacia hidrográfica e o programado para a varrição, foi necessário entender a rotina do serviço, sobretudo a distribuição das frequências. Solicitou-se ao Departamento Municipal de Limpeza Urbana (DMLU), da Prefeitura Municipal de Porto Alegre, o envio a um local específico dos sacos de logradouros previamente escolhidos.

Paralelamente, foi realizada a caracterização do resíduo que, vindo pela rede de drenagem (galerias e canais), atingia o exutório. Outro órgão da Prefeitura foi consultado, o Departamento de Esgotos Pluviais (DEP), já que o exutório coincide com o local onde se encontra uma bacia de detenção seguida de uma casa de bombas.
Dessa forma, o trabalho e os resultados são apresentados segundo os seguintes passos: (1) breve descrição da área onde ocorreu o estudo; (2) descrição da caracterização dos resíduos de varrição; (3) descrição da caracterização dos resíduos vindos pela rede de drenagem; (4) determinação da composição física global dos resíduos da varrição; (5) análise da composição física dos resíduos da varrição da bacia em função da frequência de varrição; (6) análise da composição física dos resíduos da varrição da bacia em função das campanhas de coletas de sacos de varrição (primavera-verão e outono-inverno); (7) análise conjunta da composição física dos resíduos da varrição da bacia: frequência versus campanhas; (8) análise da composição física conjunta: composição física geral dos resíduos vindos pela rede versus composição física geral da varrição.

\section{Descrição da área de estudo}

O sistema de drenagem urbana de Porto Alegre é composto por diques de proteção contra inundações, casas de bombas, condutos forçados e canais. A bacia hidrográfica estudada, entre a região central e a zona sul, drena a água para uma Bacia de Detenção (BD), e em seguida para a casa de bombas de número 12 (CB12), ambas no Parque Marinha do Brasil. A BD foi construída para amortecer o incremento de vazões provocado pela ampliação da rede de macrodrenagem da avenida Pe. Cacique, evitando-se a ampliação da capacidade de bombeamento na CB12. A área da bacia hidrográfica é de 1,92 km², com 21\% de ocupação comercial, $42 \%$ de área residencial e o restante com áreas verdes. A Figura 1 mostra a inserção dela na cidade. No detalhe, vê-se que seu contorno oeste margeia o parque e coincide com a avenida Pe. Cacique. Vê-se também parte da rede de macrodrenagem, composta de galerias e de um canal de seção trapezoidal que cruza o parque.

Durante os oito meses de estudo, verificou-se que na bacia hidrográfica havia coleta domiciliar, coleta seletiva e varrição em praticamente toda a sua área. O serviço de varrição é realizado pelo DMLU, de forma separada da coleta domiciliar. No período de estudo, a bacia

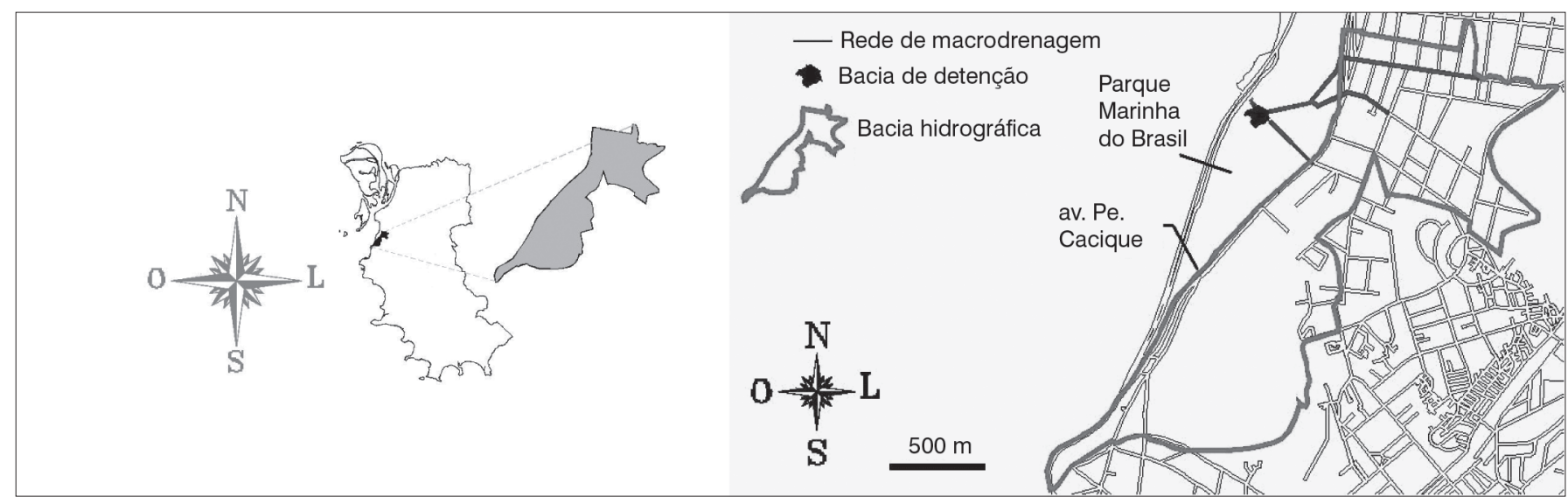

Figura 1 - Bacia hidrográfica: inserção em Porto Alegre, macrodrenagem, arruamento, Parque Marinha do Brasil e bacia de detenção (adaptado de Neves, 2006). 
hidrográfica contava com varrição diária, semanal, em dias alternados (segundas, quartas e sextas-feiras) e quinzenal; a varrição diária ocorria em duas avenidas principais, uma que corta a bacia de leste a oeste e a avenida Pe. Cacique, e a varrição nas segundas, quartas e sextas-feiras em ruas transversais às avenidas principais na região norte da bacia e também em duas ruas que cortam a região de arruamento mais denso. Nesta região, com exceção das duas ruas citadas, a varrição ocorria às segundas-feiras à noite; nas avenidas situadas no extremo sul, a varrição ocorria quinzenalmente.

\section{Procedimentos de caracterização dos resíduos sólidos de varrição da bacia hidrográfica}

Para a caracterização dos resíduos de varrição, veículos do DMLU traziam os sacos para a CB12, onde foram feitas as caracterizações. Estes sacos vieram de áreas específicas da bacia hidrográfica, previamente escolhidas. O DMLU recebia a relação de locais de onde deveriam vir os sacos, com as etiquetas correspondentes, geralmente na véspera do serviço. No dia do serviço, o varredor tomava um saco da localidade escolhida, colocava a etiqueta de identificação dentro dele, e colocava o saco em um veículo específico para levar para o local de caracterização.

A caracterização de um determinado saco foi realizada em três etapas: a primeira, separando o lixo seco de dentro dele; a segunda, derramando o material restante em um tonel com a manta plástica no seu interior e com uma peneira de malha $5 \mathrm{~cm}$, pois ainda apareciam pedaços de plásticos, papéis e outros materiais em pequena quantidade. Na terceira etapa, estendia-se a manta no chão para finalizar a separação do material. A caracterização durava cerca de uma hora por saco e por pessoa trabalhando.

Os tipos verificados na caracterização dos resíduos foram: Plásticos 1 (sacolas de supermercados, embalagens de salgadinhos, etc.); Pet (garrafas de refrigerante, etc.); Plásticos 2 (plásticos, exceto Plásticos 1 e Pet - garrafas de água mineral, potes de margarina, copos, etc.); MADT (predominantemente tocos e pedaços de galhos); Vidro (garrafas de cerveja, etc.); Papéis (jornais, panfletos, etc.); Embalagens cartonadas longa vida (caixas de leite, de suco, etc.); Isopor; Trapos (restos de roupas, tênis, sapatos, etc.); ALA (aço, latas, alumínio); Pedra (pedras que não passam na malha de $5 \mathrm{~cm}$ (peneira de obra); VAMO (vegetação, folhas, pequenos galhos, etc., areia malha de $5 \mathrm{~cm}$ - e matéria orgânica - restos de comida); e Outros (cerâmica, espuma e borracha, pedaços de ferro, couro em bolas de futebol e outros materiais - sapatos estão no item Trapos -, etc.).

\section{Procedimentos de caracterização dos resíduos sólidos vindo pela rede de drenagem}

Os resíduos sólidos carreados pela rede de drenagem eram retirados do poço da CB12 por zeladores responsáveis pela manutenção geral e limpeza do poço. Nele há uma grade de $5 \mathrm{~cm}$ de abertura. A caracterização foi iniciada em novembro de 2003. Inicialmente, planejaram-se visitas com uma frequência de duas vezes por semana, na segunda-feira e na sexta-feira. Após observações prévias, entretanto, a frequência foi aumentada, conforme o volume de resíduos. Os resíduos eram secados ao sol e depois era realizada a pesagem na mesma balança que foi utilizada para os resíduos de sacos de varrição. Os tipos já foram indicados anteriormente.

\section{Procedimentos de análises das composições}

As composições físicas mostradas nos resultados foram obtidas por médias das massas de cada tipo. O número de valores dependeu da análise. A composição física global dos resíduos de varrição, por exemplo, tomou todas as massas, em todo o período de estudo. Procurou-se assim fornecer uma visão da bacia hidrográfica em sua totalidade. A análise em função da frequência foi feita com as composições médias das massas de todo o período, para cada frequência de varrição, procurando-se observar as diferenças entre elas e a frequência diária. Quanto à composição física em função das campanhas, a análise foi realizada tomando-se os valores médios por campanha (uma no período primavera-verão e outra no período outono-inverno). O interesse nesta análise está na visualização de possíveis influências sazonais. A análise conjunta frequência versus campanhas procurou visualizar se há diferenças na composição física devidas à sazonalidade e se ainda isto ocorre de maneira diferente em logradouros de frequências de varrição distintas. Por último, procurou-se, na análise da composição conjunta varrição versus rede de drenagem, sinais de como alguns tipos de resíduos se comportam ao entrarem na rede. As análises foram realizadas com o auxílio de uma escala adotada por ICNZT (1996) em Auckland, Nova Zelândia. Nesta escala, insignificante (I) consiste na diferença inferior a 5\%; muito pequena (MP), maior ou igual a $5 \%$; pequena $(\mathrm{P})$, maior ou igual a 25\%; moderada (M), maior ou igual a 33\%; grande (G), maior ou igual a $50 \%$; e muito grande (MG), maior ou igual a $75 \%$.

\section{Resultados e discussão}

\section{Composição física dos resíduos sólidos de varrição da bacia hidrográfica}

\section{Composição física global da bacia}

Na composição física média dos resíduos das ruas, predomina o tipo VAMO com $62,2 \%$, seguido de pedras $(14,2 \%)$ e dos plásticos (9,1\%), com destaque para o tipo Plásticos 1 . A composição de papéis também é notável $(8,1 \%)$. Os 6,4\% restantes compõem-se dos demais tipos. Como a bacia hidrográfica possui uma grande área residencial (42\%) com muitas árvores, os tipos MADT, pedra e VAMO correspondem a $77 \%$ da massa. Na Tabela 1 está o resultado com somente os 
$23 \%$ restantes. Neste caso, entre os plásticos, o Pet não contribuiu muito, da mesma forma que o isopor, ALA e embalagens longa vida. Isto ocorreu provavelmente por causa da ação de catadores.

\section{Composição física em função da frequência de varrição}

A intenção desta análise é a de detectar diferenças na composição devido à frequência de varrição. A análise utilizou a escala adotada por ICNZT (1996), como mencionado no item materiais e métodos. Por exemplo, para o tipo Pet, a diferença relativa entre a composição física média na frequência diária e a composição física média na frequência alternada (segunda, quarta e sexta) foi de 94,11\%, correspondendo ao grau MG.

Os resultados qualitativos estão na Tabela 2. Toda a coluna correspondente ao tipo Pet está assinalada como MG, significando que há uma diferença muito grande na composição do Pet entre a varrição diária e as demais. Outra interpretação possível é dizer que nas avenidas principais há mais presença do tipo Pet em relação aos demais tipos, quando se compara com as demais ruas e avenidas da região da bacia hidrográfica. Outro caso: a intersecção entre a coluna Papéis e a linha segunda à noite está assinalada com I, significando que há uma diferença insignificante na composição do tipo Papéis entre a varrição diária e a de segunda à noite. De forma geral, é mais notável a predominância de plásticos (com exceção do tipo Plástico 1), Vidro e ALA nas áreas onde a varrição é diária do que nas demais.

\section{Composição física em função das campanhas}

Esta análise tomou como base as médias das chamadas campanhas, para todas as frequências de varrição. Dessa forma, obtém-se

Tabela 1 - Composição média dos resíduos de varrição da bacia em estudo

\begin{tabular}{|c|c|c|c|c|c|c|}
\hline \multicolumn{7}{|c|}{ Tipo } \\
\hline Plásticos 1 & Pet & Plásticos 2 & Vidro & Papéis & Longa vida & Isopor \\
\hline $27,7 \%$ & $3,3 \%$ & $9,0 \%$ & $5,4 \%$ & $39,1 \%$ & $1,3 \%$ & $2,1 \%$ \\
\hline Trapos & ALA & Outros & & & & \\
\hline $6,5 \%$ & $2,6 \%$ & $2,9 \%$ & & & & \\
\hline
\end{tabular}

ALA: aço, latas, alumínio; foram excluídos os dados de vegetação, areia, matéria orgânica, madeiras, tocos e pedras uma visão global da bacia hidrográfica quanto à sazonalidade. De acordo com os resultados, o tipo Plásticos 1 teve grau I de redução da presença nos sacos; Pet, MG; Plásticos 2, M; MADT, Vidro, Isopor e ALA, G; Papéis, MP; e Longa vida, Trapos, Pedra e VAMO tiveram aumento na presença. É possível explicar o que ocorreu com os descartáveis: como os meses da primeira campanha são mais quentes, o uso deles foi intensivo. O tipo Plásticos 1 é composto, em sua maior parte, por sacolas de supermercado, de consumo constante ao longo do ano.

\section{Análise conjunta frequência versus campanhas}

Esta análise é uma combinação dos casos anteriores. Procura-se visualizar se há diferenças na composição física devidas à sazonalidade, conjuntamente com a frequência de varrição. Os resultados qualitativos estão na Tabela 3. Por exemplo, o grupo ALA obteve reduções mais acentuadas, entre uma campanha e outra, nas áreas de frequência diária; ou seja, a maior participação deste tipo de resíduo na composição da varrição ocorre nos meses quentes, nas principais avenidas (varrição diária) e também nas ruas de varrição alternada, que são aquelas que fazem a ligação entre as avenidas principais e as ruas interiores, nas zonas residenciais.

Outro exemplo: para o tipo MADT ocorre diferença MG entre os meses quentes e os meses frios, nas áreas onde ocorre varrição em dias alternados e às segundas-feiras à noite. As áreas varridas uma vez por semana dizem respeito a zonas residenciais com pouco movimento e presença grande de árvores. Este mesmo tipo de resíduo apresentou diferença MP na varrição diária e I na varrição quinzenal. Pode-se dizer que a frequência diária reduz o efeito da sazonalidade e da frequência na sua participação nos resíduos. A área de varrição quinzenal possui vegetação margeando a avenida com pouco movimento de pedestres e um movimento moderado de veículos. Apesar da presença de vegetação, não há o efeito da sazonalidade e da frequência na sua participação nos resíduos. Quanto ao isopor, pode-se afirmar que, em todas as frequências de varrição, há o efeito da sazonalidade.

Tabela 2 - Grau de diferença na composição da varrição em relação à frequência diária

\begin{tabular}{|c|c|c|c|c|c|c|c|}
\hline \multirow{2}{*}{ Frequência de varrição } & \multicolumn{7}{|c|}{ Tipo } \\
\hline & Plásticos 1 & Pet & Plásticos 2 & MADT & Vidro & Papéis & Longa vida \\
\hline Alternada & $\mathrm{G}$ & MG & G & $\mathrm{P}$ & MG & M & MG \\
\hline Segunda à noite & MP & MG & $\mathrm{G}$ & MP & G & 1 & MP \\
\hline Quinzenalmente & MP & MG & $M G$ & $\mathrm{G}$ & MG & MP & $\mathrm{G}$ \\
\hline \multirow{2}{*}{ Frequência de varrição } & \multicolumn{7}{|c|}{ Tipo } \\
\hline & Isopor & Trapos & ALA & Pedra & VAMO & \multicolumn{2}{|c|}{ Outros } \\
\hline Alternada & $\mathrm{G}$ & M & MG & * & * & \multicolumn{2}{|c|}{ * } \\
\hline Segunda à noite & * & * & $\mathrm{G}$ & * & * & \multicolumn{2}{|c|}{ * } \\
\hline Quinzenalmente & * & $\mathrm{G}$ & MG & * & * & \multicolumn{2}{|c|}{ MP } \\
\hline
\end{tabular}

MADT: madeira e tocos de árvores; ALA: aço, latas, alumínio; VAMO: vegetação, areia e matéria orgânica; I: insignificante; MP: muito pequeno; P: pequeno; M: moderado; G: grande; MG: muito grande; *houve diferença negativa (aumento da participação na composição) 


\section{Composição física do resíduo vindo pela rede de drenagem}

\section{Composição física geral e relação com a composição física da varrição}

$\mathrm{Na}$ Tabela 4 está a comparação entre as composições físicas médias dos resíduos da varrição e os vindos pela rede de drenagem (lixo seco). Os Plásticos correspondem a 83\% dos resíduos na rede de drenagem. Na varrição, os plásticos correspondem a $40 \%$. Há redução dos Papéis e o aumento do Pet. Durante as pesagens, o Pet apareceu pouco nos sacos de varrição, bem como isopor e as latas de refrigerante. No entanto, o Pet apareceu nos resíduos da drenagem após precipitações fortes. Quase sempre havia papel e papelão nos sacos e raramente eles eram vistos nos resíduos da rede de drenagem. Papel e papelão se desfazem no trajeto dos condutos, preservando-se somente quando envoltos por alguma proteção. Outras análises feitas por Neves (2006) confirmam estas interpretações, ou seja, alguns tipos se desfazem na rede de drenagem e outros se acumulam até que venha uma onda de cheia e "limpe os condutos e canais".

Neves e Tucci (2008) fizeram um resumo de vários trabalhos nacionais e internacionais (ARMITAGE et al., 1998; CORNELIUS et al., 1994; ARNOLD, RYAN, 1999; ALLISON et al., 1998; BRITES, 2005; JAWOROWSKI, SCHETTINI; SILVEIRA, 2005). Os trabalhos mostram que a presença do plástico sempre é destacada. No caso das bacias hidrográficas brasileiras, de características periurbanas, a matéria orgânica é bastante marcante, por causa de deficiências da coleta domiciliar e o uso dos riachos como locais de despejos.

\section{Análise detalhada da composição do resíduo vindo pela rede de drenagem}

O indicativo de que eventos de precipitação realizam limpeza nos condutos e canais fez com que se verificasse a existência de tendências entre alguns tipos carreados pela rede de drenagem com as variáveis "número médio mensal de dias anteriores secos" e "precipitação média mensal". De acordo com os resultados, o tipo Plástico 2 não sofre influência com o número médio mensal de dias anteriores secos, enquanto o tipo Plástico 1 tende a decrescer com o aumento daquele. Os tipos Isopor e Pet tendem a aumentar suas proporções. Em relação à precipitação média mensal, as tendências não foram tão claras.

Outra análise realizada foi a da frequência de aparecimento nos dias de pesagem, para cada tipo de resíduo. De acordo com os resultados, o tipo Plástico 1 apareceu em 100\% dos dias de pesagem, o Pet $89 \%$, Plásticos $286 \%$, Trapos 54\%, Isopor 51\%, Longa vida $41 \%$ e os demais menos de $40 \%$. Isto pode indicar que o consumo de plásticos durante todo o ano se reflete na rede de drenagem.

\section{Conclusões}

Este texto expôs os resultados da caracterização dos resíduos sólidos de varrição e daqueles carreados pela rede de drenagem em uma bacia hidrográfica urbana com uso do solo preponderantemente residencial e comercial. Durante os oito meses de estudo, foram pesados resíduos de sacos de varrição e, em paralelo, os resíduos da rede de drenagem.

Os resultados mostraram que, em média, 77\% da massa dos resíduos de varrição são de vegetação, areia, restos alimentares, madeiras

Tabela 3 - Grau de redução na composição na varrição, entre as campanhas e por frequência

\begin{tabular}{|c|c|c|c|c|c|c|c|}
\hline \multirow{2}{*}{ Frequência de varrição } & \multicolumn{7}{|c|}{ Tipo } \\
\hline & Plásticos 1 & Pet & Plásticos 2 & MADT & Vidro & Papéis & Longa vida \\
\hline Diária & $P$ & MG & $\mathrm{G}$ & MP & MG & * & * \\
\hline Alternada & * & MP & M & MG & $\mathrm{G}$ & * & MG \\
\hline Segunda à noite & $\star$ & MP & M & MG & MP & MP & $\star$ \\
\hline Quinzenalmente & MP & MG & MP & I & G & MP & $P$ \\
\hline \multirow{2}{*}{ Frequência de varrição } & \multicolumn{7}{|c|}{ Tipo } \\
\hline & Isopor & Trapos & ALA & Pedra & VAMO & \multicolumn{2}{|c|}{ Outros } \\
\hline Diária & MG & * & MG & * & * & \multicolumn{2}{|c|}{ MG } \\
\hline Alternada & $\mathrm{G}$ & M & $\mathrm{G}$ & MP & * & \multicolumn{2}{|c|}{ MG } \\
\hline Segunda à noite & MG & * & * & * & * & \multicolumn{2}{|c|}{ MG } \\
\hline Quinzenalmente & & & & * & MP & \multicolumn{2}{|c|}{ * } \\
\hline
\end{tabular}

MADT: madeira e tocos de árvores; ALA: aço, latas, alumínio; VAMO: vegetação, areia e matéria orgânica; I: insignificante; MP: muito pequeno; P: pequeno; M: moderado; G: grande; MG: muito grande; *houve diferença negativa (aumento da participação na composição)

Tabela 4 - Comparação das composições da varrição e da rede de drenagem (lixo seco)

\begin{tabular}{|c|c|c|c|c|c|c|c|c|c|c|}
\hline & Plásticos 1 & Pet & Plásticos 2 & Vidro & Papéis & Longa vida & Isopor & Trapos & ALA & Outros \\
\hline Varrição & $27,7 \%$ & $3,3 \%$ & $9,0 \%$ & $5,4 \%$ & $39,1 \%$ & $1,3 \%$ & $2,1 \%$ & $6,5 \%$ & $2,6 \%$ & $2,9 \%$ \\
\hline Drenagem & $47,8 \%$ & $14,9 \%$ & $20,3 \%$ & $1,1 \%$ & $0,5 \%$ & $0,6 \%$ & $4,3 \%$ & $6,4 \%$ & $3,1 \%$ & $1,0 \%$ \\
\hline
\end{tabular}


e tocos de árvores. Isto significa que, em média, 23\% da massa de varrição é de lixo seco. Nestes $23 \%$, os plásticos do tipo Pet e outros que sofrem a ação de catadores apareceram pouco. Mostrou-se o efeito da época da análise e da frequência de varrição. De forma geral, é mais notável a presença de plásticos duros, vidro, alumínio, lata e aço nas áreas onde a frequência de varrição é diária. Na análise conjunta de frequência de varrição e época do ano, os alumínios, latas e aço têm maior participação na composição da varrição dos meses quentes, na varrição diária e também nas ruas de varrição alternada. Para o caso de madeiras e tocos de árvores, pode-se dizer que a frequência diária reduz o efeito da sazonalidade.

Quanto à composição física média dos resíduos vindos pela rede de drenagem, retirando-se os tipos vegetação, areia, restos alimentares, madeiras e tocos de árvores, pode-se dizer que os plásticos são preponderantes. Resultados mais interessantes ocorrem na comparação com os resíduos da varrição. Por exemplo, o papel e o plástico Pet não apresentaram grandes participações nos sacos de varrição, mas se acumulam na rede, aparecendo em precipitações fortes. O mesmo não ocorre com sacolas e semelhantes, sempre presentes na varrição e na drenagem por causa do consumo constante ao longo do ano. O estudo procurou contribuir para a consolidação das pesquisas na interface resíduos sólidos versus drenagem urbana.

Os autores agradecem ao Departamento Municipal de Limpeza Urbana, ao Departamento de Esgotos Pluviais, ambos da Prefeitura Municipal de Porto Alegre, ao Instituto de Pesquisas Hidráulicas da UFRGS e ao Conselho Nacional de Desenvolvimento Científico e Tecnológico (CNPq).

\section{Referências}

ALLISON, R.A.; WALKER, T.A.; CHIEW, F.H.S.; et al. (1998) From roads to rivers - Gross pollutant removal from urban waterways. Research Report for the Cooperative Research Centre for Catchment Hydrology, Australia, 98 pp.

ARMELIN, L.F. (2005) A questão do acúmulo de resíduos sólidos em bacias de detenção urbanas na região metropolitana de São Paulo. 128f. Dissertação (mestrado em Engenharia) - Escola Politécnica da Universidade de São Paulo, São Paulo.

ARMITAGE, N.; ROOSEBOOM, A.; NEL, C.; et al. (1998) The removal of urban litter from stormwater conduits and streams. Water Research Commission. Report No. TT 95/98, Pretoria.

ARNOLD, G.; RYAN, P. (1999) Marine Litter originating form Cape Town's residential, commercial and industrial areas: the connection between street litter and storm-water debris. A co-operative community approach. Island Care New Zealand Trust, C/- Department of Geography, The University of Auckland, New Zealand. Percy FitzPatrick Institute, University of Cape Town.

BRITES, A.P.Z. (2005) Avaliação da qualidade da água e dos resíduos sólidos no sistema de drenagem urbana. 177f. Dissertação (mestrado em Engenharia Civil, área de concentração Recursos Hídricos e Saneamento Ambiental) - Universidade Federal de Santa Maria, Santa Maria.

CORNELIUS, M.; CLAYTON, T.; LEWIS, G. et al. (1994) Litter associated with stormwater discharge in Auckland city New Zealand. Auckland: Island Care New Zealand Trust.

ISLAND CARE NEW ZEALAND TRUST. (1996) Reducing the incidence of stormwater debris and street litter in the marine environment: a co-operative community approach. Auckland: Island Care New Zealand Trust.
JAWOROWSKI, A.L.O.; SCHETTINI, E.B.C.; SILVEIRA, A.L.L. (2005) Qualidade da água e caracterização de resíduos sólidos em arroio urbano da região metropolitana de Porto Alegre. In: Simpósio Brasileiro de Recursos Hídricos, 16., 2005, João Pessoa (PB). Anais. São Paulo: ABRH, 2005. 1 CD-ROM.

MARAIS, M.; ARMITAGE, N. (2004) The mensurament and reduction of urban litter entering stormwater drainage systems: paper 2 - Strategies for reducing the litter in the stormwater drainage systems. Water $S A, n$. 4. v. 30. Disponível em: www.wrc.org.za. Acesso em 05 de setembro de 2006

NEVES, M.G.F.P. (2006) Quantificação de Resíduos Sólidos na Drenagem Urbana. 2006. 249 f. Tese (doutorado em Recursos Hídricos e Saneamento Ambiental) - Universidade Federal do Rio Grande do Sul, Porto Alegre.

NEVES, M.G.F.P; TUCCI, C.E,M. (2008); Resíduos sólidos e drenagem urbana: estudo de caso. Revista Brasileira de Recursos Hídricos, v. 13 , n. 4, p $43-54$

SCHUELLER, T. (1987) Controlling Urban Runoff: a Practical Manual for Planning and Designing Urban BMPs. Washington: Metropolitan Washington Council of Governments. 229p.

SILVEIRA, A.L.L. (2001) Problems of urban drainage in developing countries. In: International Conference on Innovative Technologies in Urban Storm Drainage, 1, 2001, Lyon. Novatech, p. 143-150.

TUCCI, C.E.M. (2002) Gerenciamento da Drenagem Urbana. Revista Brasileira de Recursos Hídricos, v. 7, n.1, p 5-28. 